\title{
Wafer scale coating of polymer cantilever fabricated by nanoimprint lithography
}

Greve, Anders; Dohn, Søren; Keller, Stephan Urs; Vig, Asger Laurberg; Kristensen, Anders; Nielsen, Claus Højgård; Larsen, Niels Bent; Boisen, Anja

Published in:

2010 IEEE 23rd International Conference on Micro Electro Mechanical Systems (MEMS)

Link to article, DOI:

10.1109/MEMSYS.2010.5442334

Publication date:

2010

Document Version

Publisher's PDF, also known as Version of record

Link back to DTU Orbit

Citation (APA):

Greve, A., Dohn, S., Keller, S. U., Vig, A. L., Kristensen, A., Nielsen, C. H., Larsen, N. B., \& Boisen, A. (2010). Wafer scale coating of polymer cantilever fabricated by nanoimprint lithography. In 2010 IEEE 23rd International Conference on Micro Electro Mechanical Systems (MEMS) (pp. 612-614). IEEE.

https://doi.org/10.1109/MEMSYS.2010.5442334

\section{General rights}

Copyright and moral rights for the publications made accessible in the public portal are retained by the authors and/or other copyright owners and it is a condition of accessing publications that users recognise and abide by the legal requirements associated with these rights.

- Users may download and print one copy of any publication from the public portal for the purpose of private study or research.

- You may not further distribute the material or use it for any profit-making activity or commercial gain

- You may freely distribute the URL identifying the publication in the public portal 


\section{WAFER SCALE COATING OF POLYMER CANTILEVER FABRICATED BY NANOIMPRINT LITHOGRAPHY}

Anders Greve, Søren Dohn, Stephan Keller, Asger L. Vig, Anders Kristensen, Claus

H. Nielsen, Niels B. Larsen and Anja Boisen

Technical University of Denmark, Denmark

\begin{abstract}
Microcantilevers can be fabricated in TOPAS by nanoimprint lithography, with the dimensions of $500 \mu \mathrm{m}$ length $4.5 \mu \mathrm{m}$ thickness and $100 \mu \mathrm{m}$ width. By using a plasma polymerization technique it is possible to selectively functionalize individually cantilevers with a polymer coating, on wafer scale by using a shadow masking technique.
\end{abstract}

\section{INTRODUCTION}

Cantilever-based sensors are most often used to detect changes in surface stress upon binding of specific target molecules to the surface. Cantilevers are traditionally fabricated in silicon-based materials, by moving to softer materials such as polymers the cantilevers can become more sensitive and cheaper [1]. By using NIL (NanoImprint Lithography) to fabricate cantilevers almost any 3D structure, for signal enhancement can be implemented into the silicon stamp and transferred to the cantilever surface [2]. It is hereby possible to realise the cantilever in thermoplasts like TOPAS. Another challenge for cantilever sensing which has received very little focus is specific functionalization on a larger scale. Functionalization is often done on individual chips and by hand. Here we present the NILbased fabrication of TOPAS cantilever and a shadow mask technique to functionalize individual cantilevers on a wafer scale.

\section{FABRICATION}

The first step is to fabricate the stamp for the NIL, which is done by standard silicon processing. First a shallow reactive ion etch (RIE) is performed to a depth of $800 \mathrm{~nm}$. This step defines substructures for the cantilever surface. A second RIE step with an etch depth of $5 \mu \mathrm{m}$ is used to define the outline of the cantilever. Finally, the stamp is coated with a durable antistiction coating, FDTS (1H,1H,2H,2H- perfluorodecyltrichlorosilane) which is bound covalently to the silicon surface [3], see Figure 1a.
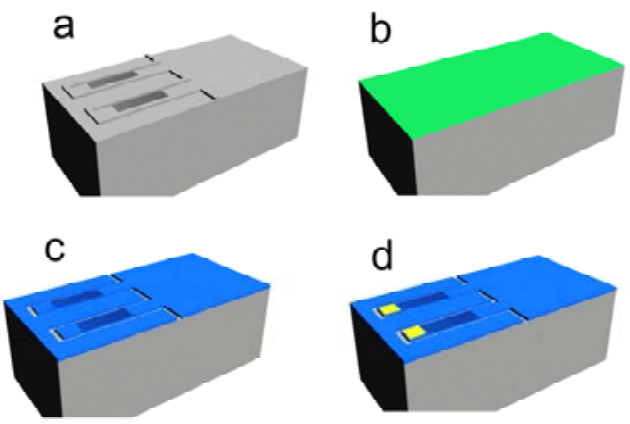

e

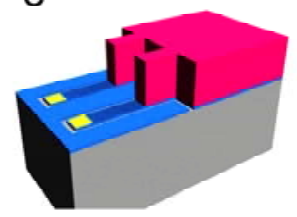

f

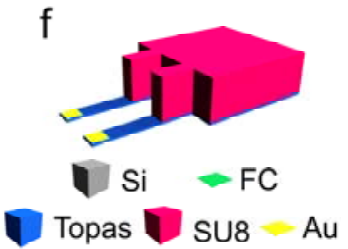

Figure 1. (a) shows the silicon stamp. (b) shows the silicon wafer with the FC coating, and (c) shows after the NIL of the Topas layer and residual etch. $5 \mathrm{~nm}$ Ti and $20 \mathrm{~nm}$ $\mathrm{Au}$ is patterned at the end of the cantilever (d). The support structure is defined in a $250 \mu \mathrm{m}$ thick layer of SU-8 (e) and finally the individual chips can be lifted of and the cantilever are released (f).

For the cantilever imprint the first step is to deposit a thin layer of fluorocarbon (FC) on a silicon carrier wafer. The FC layer is deposited in the Advanced Silicon Etch (ASE) machine, by running a passivation cycle for $1 \mathrm{~min}$. [1]. Next a $6 \mu \mathrm{m}$ layer of Topas (mr-I T85-5.0 XP) is spun on and imprinted with the stamp at 170 ${ }^{\circ} \mathrm{C}$ at $15 \mathrm{kN}$ for $30 \mathrm{~min}$. The residual layer is etched an oxygen plasma, in the RIE to ensure an anisotropic etch and hence minimum damage to the structures. A gold pad $(20 \mathrm{~nm}$ thick) is defined at the apex of the cantilever by a lift off process a $5 \mathrm{~nm}$ titanium layer is used for adhesion between the TOPAS and the gold. The metal pad is used for optical readout of the cantilever deflection. Next step is a thick layer of SU-8 2075 that is spun on the wafer to a thickness of $250 \mu \mathrm{m}$, by UV lithography the body chip is defined in this layer. Finally the finished chip with cantilevers can be lifted of the FC layer mechanically by a tweezer, see 
Figure 1b-f. One 4" wafer contains just over 300 chips, with the current design. The finished cantilever is shown in figure 2 , if the metal is not needed for the readout the step can be skipped and the process is even faster.

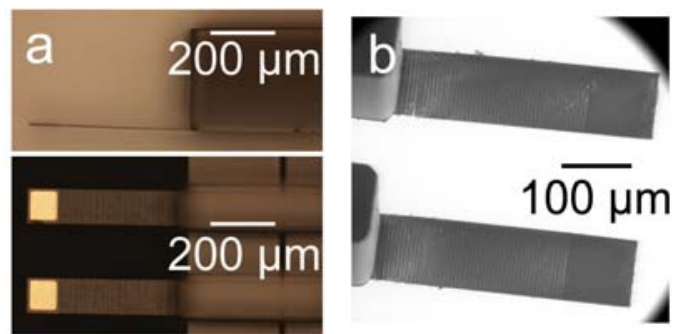

Figure 2. (a) Optical images of the top and side view is shown in, they are $500 \mu \mathrm{m}$ long and have a gold coated apex. (b) shows two rippled cantilevers, the ripples have a pitch of $4 \mu \mathrm{m}$.

The shadow mask requires two masks, the start is a $350 \mu \mathrm{m}$ thick silicon wafer. The first step is to define which cantilever to functionalized, and etch a hole through the wafer by DRIE (Deep Reactive Ion Etch). The second etch defines a cavity for the SU8 support, the same mask that was used for the thick SU8 layer is used again. The final step is to etch $25 \mathrm{~min}$ in $\mathrm{KOH}$ at $80{ }^{\circ} \mathrm{C}$, this allows for easier mechanical alignment, the finished shadow mask is shown in Figure 3.
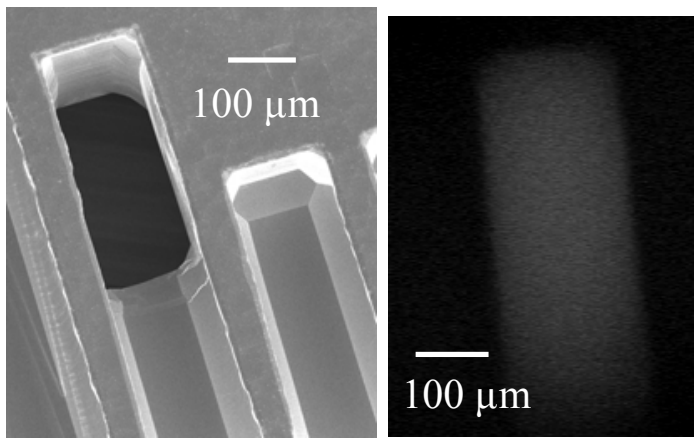

Fig. 3. The left picture is a SEM picture of the finished shadow mask. The black hole indicates the area for functionalization. The right picture shows a fluorescent image of MAH after polymerization through the shadow mask on to a blank surface.

\section{FUNCIONLIZATION AND MEASUREMENTS}

For the functionlization the shadow mask is placed on top of the wafer with the cantilever chips, see Figure 4, and placed in a plasma chamber [4]. The polymer MAH is deposited onto the exposed cantilevers over the entire wafer.
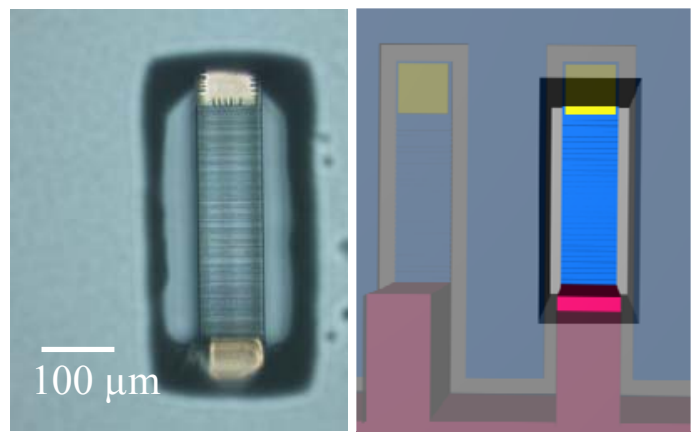

Fig. 4. On the left is an optical image of a cantilever seen through the shadow mask opening. On the right is a graphical illustration, showing the shadow mask as transparent and the same chip as shown in Figure 1e.

MAH absorps water and therefore it is easy to demonstrate a succesful deposition by introducing humidity and monitoring the bending of a coated and an uncoated cantilever, see Figure 5.

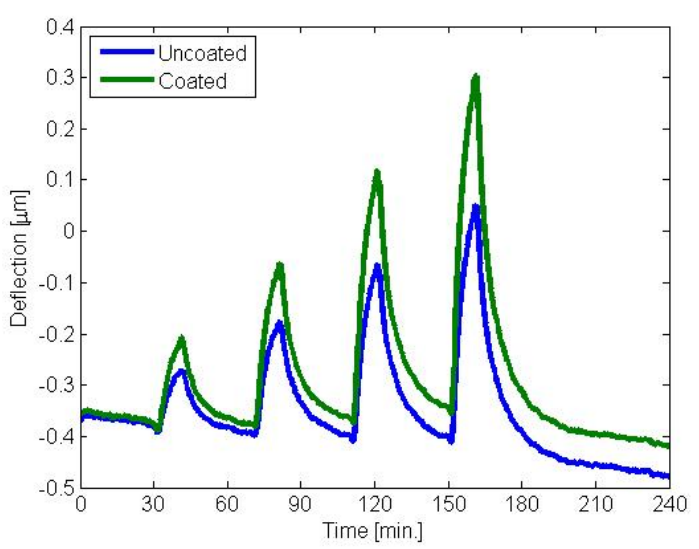

Fig. 5. This graph shows the deflection of two cantilevers. The green top line is for the coated, while the blue line is the uncoated. The four peeks correspond to increases in humidties, from $5,10,15$ and $20 \%$. It is clear how the coated cantilever gives a larger response compared to the uncoated.

Due to processing the two sides of the cantilever are different, which result in a response to humidty eventhough it is not coated. For meaningfull sensing it is important to use an uncoated cantilever as a base and subtract it from the coated cantilever, see Figure 6 . The amplitude and reaction rate can directly be correlated to the concentration, see Figure 6. More chips has been tested from the same wafer and they yield very similar response. 


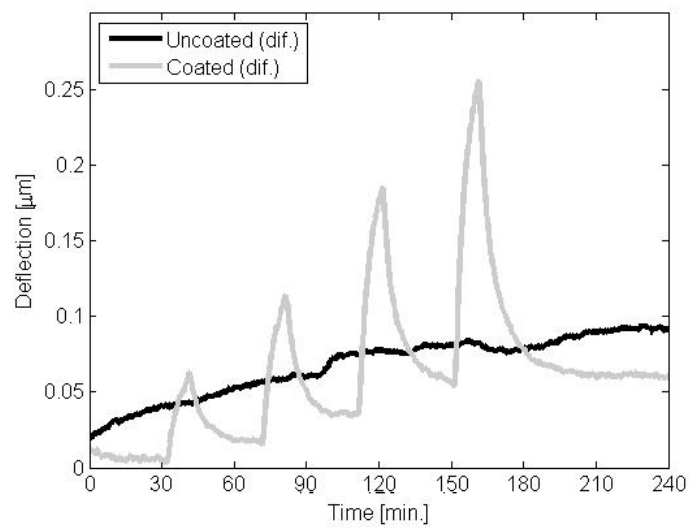

Fig. 6. By subtracting the response from the two cantilevers (shown in Figure 4) the response is almost perfect linear to the changes in humidty (Coated (dif.)). When measuring on two uncoated cantilevers there is no differential signal (Uncoated (dif.)).

\section{CONCLUSION}

In conclusion we have demonstrated that we can fabricate cantilevers by nano imprint lithography. We can functionalize them on a wafer scale coating several hundred chips at the same time, and the tested model coating gives a clear signal from humidity.

Corresponding author:

DTU Nanotech - Department of Micro and Nanotechnology, Technical University of Denmark, bldg. 345 east, 2800 Kgs. Lyngby, Denmark; E-mail: agre@nanotech.dtu.dk

\section{References:}

${ }^{1}$ S. Keller, D. Haefliger and A. Boisen 2007 J. of Vac. Sci. and Tech. B 625

2 J. J. Headrick, M J, Sepaniak, N. V. Lavrik and P. G. Datskos 2003 Ultramicroscopy, 97, $1-4$

${ }^{3}$ Zhang T, Kobrin B, Wanebo M, Nowak R, Yi R, Chinn J, Bender M, Fuchs A and Otto M 2006, Proceedings Of The Society Of PhotoOptical Instrumentation Engineers (SPIE) 6151 15117-15117.

${ }^{4}$ Patent: B. Winther-Jensen and K. West, WO 2005/092521 A2 